\title{
The Impact of Technological Innovation and Sustainable Development on the Quality Competitiveness of Manufacturing Industry
}

\author{
Shicheng Pan ${ }^{1}$, Ting Wang ${ }^{1,}$, Ke Wang ${ }^{2}$ \\ ${ }^{1}$ Department of Management, University of Guizhou, Guiyang, China \\ ${ }^{2}$ Department of Management, University of Guizhou, Guiyang, China \\ *1396708997@qq.com
}

Keywords: Quality Competitiveness, Sustainable, Technology Innovation, Manufacture Industry

Abstract: Technological innovation and sustainable development have become two important factors that could promote economic development. But how do technological innovation and sustainable development affect quality competitiveness? The role of technological innovation and sustainable development on quality competitiveness has been analysed in this paper based on previous studies about quality competitiveness of other scholars. By collecting relevant data between year 2006 and 2014, using the software of SPSS to construct linear regression model and the result suggests that technological innovation and sustainable development have positive effect on the quality competitiveness. In addition, technological innovation and sustainable development both have a liner relationship with quality competitiveness.

\section{Introduction}

The China Manufacturing 2025, the first ten years' programmer of action, is a strategy which helps China's manufacture steps into the top of manufacture. China has always been taking the scientific and technological innovation, the sustainable development, the industrial structure and the cultivation of talents as the basic policy of development. Manufacturing industry is the main economy component of Chinese and the comprehensive reflection of China's comprehensive national strength. Quality competitiveness is the best embodiment to measure the level of industrialization of manufacturing and comprehensive strength.

Manufacturing industry is a technology intensive industry, although the overall stage of China's manufacturing industry developed rapidly, in fact, it has shown "big but not strong" situation. Manufacturing production has a high requirement to improve manufacturing quality competitiveness both from the integration of resources, technological process and technological innovation. Therefore, enterprise should not only focus on technology innovation and the introduction of talent, but also to strengthen their information transmission and regulation.

From the macroscopic or microscopic perspective, manufacturing quality competitiveness has been aroused comprehensive attention. With the progress of modern science and technology, the 
technology innovation has been become mature. Only through comprehensive reforming and breaking an amount of barriers can enterprises improve their quality development.

\section{Theory and Research Hypothesis}

The history of quality research can be traced back to the 20th century, but there are just several decades since people researched the quality competitiveness. (K.Aiginger 1997) the quality competitiveness of has attracted the attention of scholars in different fields since it was raised up. Quality competitiveness covers medicine, economy, service, finance and other areas (Kumara 2002, Beaumot 1993. K Greenan 1997). The most representative is the quality competitiveness evaluation model (QCI) which was proposed by Kumara which combined qualitative and quantitative method to measure the quality competitiveness (Kumara 2002). Compared with foreign countries, the domestic quality competitiveness studies were late. Quality competitiveness was introduced to the domestic in 2000 for the first time (Xiaofen Tang 2002), after the China promulgated the evaluation index system of the quality competitiveness, From the initial induction, building of quality competitiveness elements (Decheng Wen 2005, Jiadong Jiang 2004) relevant algorithm model test (Hongwei Yu 2015) to solve some problems in industries that it shows the research and application of quality competition in our country is mature gradually.

It is concluded that domestic and foreign scholars have been made a great progress in the research of quality competitiveness, but domestic research pay more attention to about the construction of index system, the research on the impact of specific influencing factors. Based on the domestic quality competitiveness index model, technological innovation and sustainable development are considered as influencing factor. Data were collected from 2006 to 2014, to analyze the relationship between them and quality competitiveness of manufacturing industry.

\subsection{Technological Innovation and Quality Competitiveness}

Innovation is the soul of national development and as an important element to enhance the competitiveness of a company or a country. Technological innovation has changed the traditional production model of high consumption, heavy pollution, high cost, low efficiency, to reduced emissions, and then achieved a win-win situation. We should strengthen the research between development strategy of innovation and practical application, clarify the value and strategic focus of innovation, and choose the relevant strategy as the development model of China's economic transformation (Liangqun Qi 2014). As for how the innovation efficiency impact on the quality of competitiveness, the relevant researches mainly consider from the number of innovative activities, funds and resources (Hong Cheng 2015). Technological innovation can provide a source for the product design, functional development, cost management and production technology and bring new competitiveness for an organization as an important component of the enterprise (Yuxi Liu 2015). Technological innovation as an important part of the competiveness of enterprises and has an irreplaceable role, of course it is the integration of existing technologies, integration of product structure optimization and value process transformation. As an important component of the enterprise, technology innovation in product design, function development, cost management, change the production technology, can bring changes to the commodity itself and can bring new competitive power for enterprises.

Hypothesis 1: The higher the quality of innovation, the stronger the quality of competitiveness.

\subsection{Sustainable Development and Quality Competitiveness}

Low emissions, consumption, zero pollution and high efficiency, high benefit is the goals of 
manufacturing How to achieve dynamic transformation of green development from the "black box" model to the "green" mode, it is still the primary task to realize a win-win of economic and ecological (Hefeng Tong 2015). On the one hand, the industry should be planned and coordinated from the perspective of national and regional green development (Yi Sun 2012); the other hand, in order to achieve maximum efficiency (Kexin Bi 2014), enterprises must achieve the harmony of development, coordination and sustainability in the use of resources and form the green process and recycling (Yunping Chen 2012). It isn't difficult to find out that the improvement of the competitiveness of enterprises or countries is closely related to sustainable development. It can be roughly summarized that the main factors affecting the green competitiveness are resources, culture, continuity, innovation, circulation, system and policy. A second hypothesis is placed on the relationship between sustainable development and quality competitiveness:

Hypothesis 2: The higher the capacity for sustainable development, the higher the quality of competitiveness will be.

\section{Methodology}

\subsection{Variable Declaration}

This research focuses on the impact of technological innovation capability and sustainable development ability on quality competitiveness. Three variables are defined, a target variable and two auxiliary variables.

Target variable: quality competitiveness (Y)

Although the quality competitiveness is the ability to show excellent quality advantage, in fact, it is an abstract concept. Since 2005, the Quality Competitiveness Index Bulletin was jointly built by the AQSIQ and the National Bureau of Statistics to describe the index of industrial competitiveness over the years. Corresponding national competitiveness index, competitiveness index of different industries as well as regional quality competitiveness index by region which was built by data collected including 250 thousand enterprises in 29 industries of 31 provincial capitals was gained based on range differences of data gathered.

Auxiliary variable: technical innovation (X1)

The capability of technological innovation is manifested by innovation index, and the level of innovation index reflects not only the overall level of the country, but also the direction of the future development of the country. The China Innovation Index Report which consists of 21 indices in 4 areas was launched in 2005 and it is used to represent the overall performance of national innovation capacity by changes in various fields. Innovation index was introduced into our country in the same year and the initial value is defined as 100 . This study collects data from the Bulletin of the innovation index in China and statistics annual national innovation index values from the year 2006 to 2014, and it is set as one of the independent variable factors.

Auxiliary variable: sustainable development ability (X2)

The sustainable development of our society is confronted with three dimensions: the mode of economic growth, the environment of ecological resources and the accumulation of human capital .Sustainable development ability can be seen as a unification of various abilities. In this research, through setting the comprehensive utilization of industrial solid as an indicator of sustainable development ability. Industrial solid waste comes from the industrial production and industrial production waste, dust, and other debris. Rate of comprehensive utilization of industrial solid waste (W1) refers to the percentage of industrial solid waste production (W2) of total industrial solid waste (W3).

$$
\text { Formula: W1= W2 / ( W3 +W4) *100\% }
$$


W4: Comprehensive utilization of stocks in previous years

\subsection{Data Sources and Model Building}

Quality competitiveness index of this article from the Bulletin of National Manufacturing Competitiveness Index, innovation index derived from the Index Research Reports of China, the rate of comprehensive utilization of industrial solid waste comes from the Statistical Yearbook of China. The difference of index from 2006 to 2014 witch is shown in Fig 1.

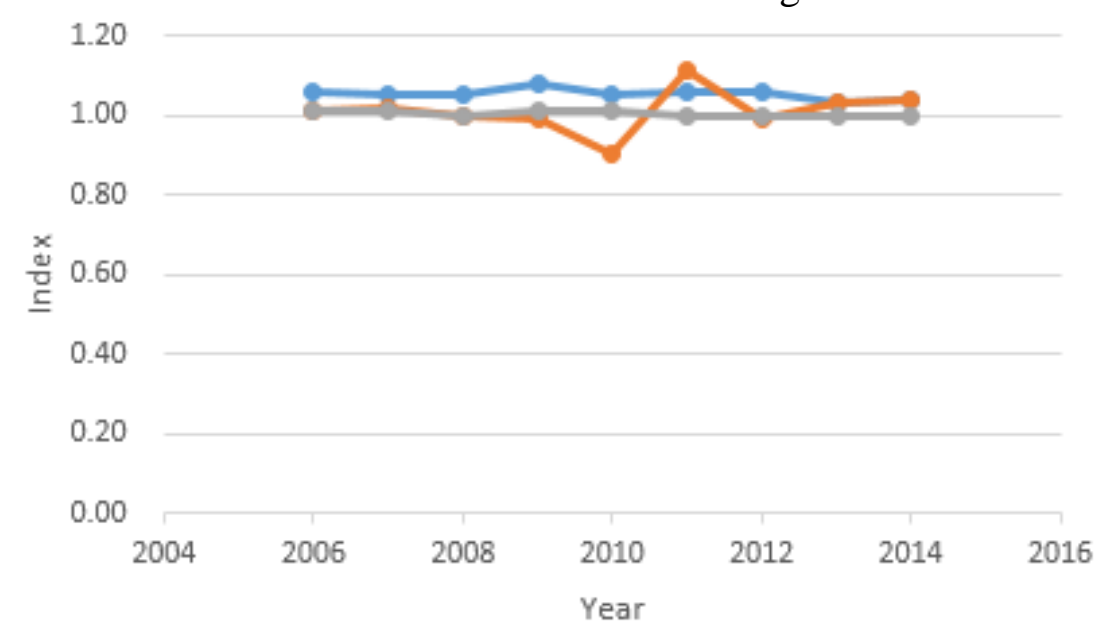

Fig 1. Innovation, Development and Quality Date from 2006 to 2014

(The blue is represented the innovation, the gray represented the quality and the orange represented the sustainable development). Showing from Table1.(1)The quality competitiveness index, the technology innovation index and the sustainable development index are all positive, which indicates that they are on the rise. (2)The growth of three indicators is consistent. If the two hypotheses are established, the following linear mathematical model is constructed.

$$
Y(Q C I)=\mathbf{a} * X_{1}(C I I)+\mathbf{b} * X_{2}(R C D I)+\mathbf{c}
$$

QCI: quality competitiveness index; CII: China Innovation Index; RCDI: Comprehensive utilization of industrial solid waste; a: the CII elasticity relative to the quality competitiveness index; b: the RCDI elasticity relative to the quality competitiveness index; c: random disturbance of the system

\subsection{Data Check and Analysis}

Then using the 22 version of SPSS software to perform linear regression analysis of the data collected used to analyze the constructed model. The results are shown in Table 1

Table 1 The Result of the Linear Regression Model

\begin{tabular}{ccccc}
\hline $\begin{array}{c}\text { Mode } \\
1\end{array}$ & $\mathrm{R} 2$ & $\mathrm{df} 1$ & $\mathrm{df} 2$ & $\mathrm{~F}$ \\
1 & 0.933 & 2 & 7 & 0.005 \\
\hline
\end{tabular}

From the results in Table1, the $F=0.005$, so there is a relationship between quality competitiveness, technological innovation and sustainable development. Therefore, they can be represented by the constructed linear regression model. The $\mathrm{R} 2=0.933$, which indicates that the information of the quality of competitiveness can be fully extracted. It is necessary to analyze the 
numerical values of the corresponding influence coefficients. The results are shown in the Table 2

Table 2. Sustainable development and the coefficient of technological innovation

\begin{tabular}{cccccc}
\hline \multirow{2}{*}{ Model } & \multicolumn{2}{c}{ Unstandardized Coefficients } & \multirow{2}{*}{ Beta } & \multirow{2}{*}{$\mathrm{t}$} & Sig. \\
\cline { 2 - 3 } & $\mathrm{B}$ & $\mathrm{S} . \mathrm{E}$ & & & \\
\hline constant & 0.000 & 0.043 & 0.000 & 0.00 & 1.00 \\
DV & 0.043 & 0.121 & 0.043 & 0.981 & 0.021 \\
TI & 0.559 & 0.221 & 0.559 & 2.535 & 0.039 \\
\hline
\end{tabular}

From Table 2, all the $\mathrm{P}$ values are less than 0.05 , it can be considered that the linear relationship between sustainable development and technological innovation and quality competitiveness is significant, therefore, a linear equation can be established. And from the Table 2, the constant(c) which equal to 0 , and the sustainable development coefficient is 0.043 , the technical innovation coefficient is 0.559 . So the model constructed can be expressed as:

$$
Y(Q C I)=0.559 * X_{1}(C I I)+0.043 * X_{2}(R C D I)
$$

The model shows that if sustainable development remains stable, a unit of technological innovation index changes, the quality competitiveness index will also be changed approximately 0.559 per unit. Therefore, the higher the technological innovation ability, the better the quality competitiveness, so the hypothesis 1 is valid. Similarly, under the condition of innovation ability is not constant, the unit sustainable development index changes, the quality competitiveness index is floating in 0.043 per unit, so the higher the sustainable development ability, the stronger the quality competitiveness , therefore, the hypothesis 2 is established.

Technology innovation and sustainable development are the two factors, which can enhance the quality competitiveness. According to this research, China's manufacturing industry restructuring and upgrading would follow two suggestions: 1. strengthen the strategy of rejuvenating the country, encourage innovation and entrepreneurship referendum; 2. strengthen the industrial upgrading and transformation, to achieve green production

\section{Conclusions}

Through reviewed the related literature based on the present status of technology innovation and sustainable development of equipment manufacturing industry research and then collecting the cross-sectional data, which are 10 years of the quality competitiveness index, index of technological innovation and sustainable development index. After that, then use the SPSS to construct linear regression model, and reveal the internal mechanism of the three. The main contribution of this study: 1. in theoretical analysis, the positive effect of innovation and sustainable development on quality competitiveness is verified; 2 . from the perspective of both internal and external factors, regard technology innovation and sustainable development as the influencing factors which affect quality competitiveness. By constructing a linear model, the relationship between the three is clarified.

Due to the limitations of this study, the following factors will be considered in future research: 1 . extending the scope of time, making the data more complete and the analysis results more representative; 2.there are many factors affecting the quality competitiveness, which requires deep exploration of the inter-relationship between quality competitive-ness factors.

\section{Acknowledgements}

Supported by major project fund for social science \& humanities of Guizhou University, NO 


\section{GDZT201702;}

The Soft Science Research plan of Guizhou province (project number: 2016 GZ1519-4) and the Project of Guizhou Province Science and Technology Innovation Activities Abroad (2015 No. 19).

\section{References}

[1] Beaumot, “Anemployee Survey Measuring Total Quality Management Practices and Culture”, Group and Organization Management, vol.22, no.4, pp.414-444, 1993.

[2] Decheng Wen,"Research on Product Quality Competitiveness and its Components", World Standardization and Quality Management, no.06, pp.4-8, 2005.

[3] Hefeng Tong, Yang Yang, Jingyi Wang,Ying Feng, "Modeling China's Green Economy 2050:Scenario Analysis Based on the System Dynamics Model", China Soft Science, no.06, pp.20-34, 2015

[4] Hong Cheng, Chuan Chen, "Theory Analysis and Model Building of Manufacturing Quality Competitiveness", Chinese Journal of Management, vol.12, no. 11, pp. 1695-1702, 2015

[5] Hongwei Yu, De-zhuang Hu "Research on China Regional Manufacturing Quality Competitiveness Evaluation and Influencing Factors Analysis Base on Three-Stage DEA Model”, Chinese-Journal-of Management, vol.12, no.11, pp. 1703-1709, 2015.

[6] Jiadong Jiang,”The Quality Competitiveness Index (QCI) Analysis “, Aeronautic Standardization \& Quality, no.1, pp.13-14, 2004.

[7] K Greenan , P Humphreys, $R$ Mcivor, ” The Green Initiative : Improving Quality and Competitiveness foe European SMEs”, European Business Review, vol.97, no.97, 1997.

[8] K.Aiginger, 1997. "The Use of unit values to discriminate between price and quality completion”, Cambridge Journal of Economics, 21(5) pp. 571-592, 1997

[9] Kexin Bi, Yuhan Wang, Chaojun Yang, "Effect of Innovation Resources Input on Green Innovation Capability of Green Innovation System: Empire", China Soft Science, no.03, pp.153-166, 2014

[10] Kumara, Stecke.K.E, Motwani J, “A Qualit y Index -Based Methodology for Improving Competitiveness: Analytic ical Development and Empirical Validation [M], 2002, pp.34-267.

[11] Kumara, Kathpynes, Matawan, "A quality index-based methodology for improving competitiveness: analytical development and empirical validation”, [Book Style]. Michigan: Business School, University of Michigan, 2002, pp.12-43.

[12] Liangqun Qi, Chengdong Wang, Yuanyuan, Cai "R\&D Efficiency Evaluation and Influence Factors of Chinese Equipment Manufacturing Industry", R\&D Management, vol.26,no.01,pp.111-118,2014

[13] Xiaofen Tang,"A Study on Quality Competence", The 8th Conf of the APQO, no.10, pp.151-157, 2002.

[14] Yi Sun, Puqiu Jing, "A study on green transition mode and transition path of resource - based regions", China Soft Science, no.12, pp.152-161, 2012.

[15] Yunping Chen , Xiaoyong Huan, “Exploratory analysis of factors affecting regional green competitiveness”, Macroeconomics , no.12,pp.60-67,2012

[16] Yuxi Liu, Jiaping Xie, "Business Model Innovation of Manufacturing Enterprises under the Strategy of Sustainable Development", Science of Science and Management of S.\& T., vol.01, no.36, pp.53-62, 2012 